\title{
A valorização imobiliária em Belo Horizonte, 1995-2012: uma análise hedônica-quantílica
}

\author{
Belo Horizonte's real estate valuation, 1995-2012: a hedonic-quantile approach
}

\author{
Luiz Andrés Ribeiro Paixão (1) \\ Viviane Luporini (2) \\ (1) Instituto Brasileiro de Geografia e Estatística \\ (2) Universidade Federal do Rio de Janeiro
}

\section{Abstract}

This paper estimates quantile hedonic price indexes for apartments in Belo Horizonte, Brazil, 1995-2012. From an urban economic point of view, the real estate is one example of a segmented market and for this reason we choose the quantile regression approach. The several results suggest that before 2004, when there was a lack of institutional mark for the real estate mortgages and macroeconomics environment was too uncertain, there a little appreciation in apartments prices. In this period there wasn't a regular pattern in quantile appreciation. Since 2005, there was a great appreciation of apartments in all segments of the market, since the real estate mortgage increases due to the reformulation of the real estate mortgage institutional market. Before 2009, the appreciation was more pronounced in the highest segments. Since 2009, there was a reversion of the quantile appreciation pattern. The appreciation in lowest segments was higher than in the highest. Partly, this change can be attributed to countercyclical policies implemented by Brazilian Government which focus on families with medium and low incomes.

\section{Keywords}

real estate market, price indexes, hedonic prices, quantile regression.

JEL Codes R21, R31, C1.

\section{Resumo}

Este trabalho tem como objetivo estimar indice de preços hedônicos-quantílicos para o mercado de apartamentos em Belo Horizonte, entre 1995 e 2012. A técnica de regressão quantílica foi utilizada pelo fato de o mercado imobiliário ser segmentado. Os resultados indicam que até 2004 a valorização imobiliária foi modesta. Contribuíram para esses resultados a falta de um marco institucional para o Sistema Financeiro da Habitação (SFH) e o ambiente macroeconômico incerto. Por essa razão, não houve um padrão para a valorização imobiliária nos diversos quantis. A partir de 2005, a valorização imobiliária foi intensa em todos os segmentos. Até 2009, os segmentos superiores exibiram maiores taxas de valorização. A partir de 2009, houve uma reversão desse padrão de valorização nos quantis, e os apartamentos dos segmentos inferiores passaram a exibir maior valorização. Parte dessa mudança pode ser atribuida às políticas anticíclicas adotadas pelo Governo Federal para atenuar os efeitos recessivos da crise mundial.

\section{Palavras-chave}

mercado imobiliário, indice de preços, preços hedônicos, regressão quantílica.

Códigos JEL R21, R31, C1. 


\section{Introdução}

A partir da segunda metade dos anos de 2000 houve uma intensa valorização imobiliária no Brasil. Mudanças no mercado de crédito habitacional, como a regulamentação do instituto da alienação fiduciária, somadas à queda na taxa de juros e ao aumento da renda, impulsionaram a demanda por imóveis. Demanda esta que se encontrava reprimida pela pequena oferta de crédito imobiliário, devido à falta de um marco institucional claro para o sistema de financiamento da habitação, e ao ambiente macroeconômico turbulento do final dos anos de 1990 e primeiros anos de 2000, marcado por crises internacionais que contagiaram a economia nacional, por política monetária restritiva e pelo baixo crescimento da renda das famílias.

O comportamento recente do mercado imobiliário brasileiro lançou luz à questão da ausência de um índice de preços imobiliário oficial e à necessidade de se construir índices de preços para imóveis. Surgiram, nos últimos anos, dois índices de imóveis que ganharam projeção nacional, embora não sejam oficiais. $O$ índice FipeZap de imóveis anunciados, divulgado pela Fundação Instituto de Pesquisa Econômica (FIPE) e o Índice de Valores de Garantia de Imóveis Residenciais Financiados (IVG-R), divulgado pelo Banco Central do Brasil (BCB) a partir de 2013. Embora esses índices representem valiosa fonte de informação sobre o comportamento dos preços dos imóveis no Brasil, algumas lacunas persistem. Primeiramente, nenhum deles fornece informação para períodos anteriores a março de 2001. Em termos de método, ambos utilizam a mediana estratificada. Porém, existe um consenso na literatura de que índices estimados a partir de modelagem econométrica geram resultados mais robustos (Diewert, 2009).

Índices consagrados como S\&P/Case-Shiller Home Price Index, publicado nos Estados Unidos (EUA), e índices divulgados por institutos oficiais de estatística como The New House Price Index, dos EUA, Índice de Precios de Viviendas, Espanha, e Conseil Supérieur du Notarist House Price Index, da França, são exemplos de índices de preços mensurados através de modelos econométricos. A estimação de índice de preços para imóveis, por meio de métodos de regressão, tem sido comum na literatura acadêmica, como nos trabalhos de Gatzlaff e Ling (1994), Hoesli, Giaccotto e Favarger (1997), Hill, Melser e Syed (2009), Maurer, Pitzer e Sebastian (2004) e Pavese (2007). Existem algumas aplicações para a realidade brasileira, como os trabalhos de González (1997), Rozenbaum e Macedo-Soares (2007), Ro- 
zenbaum (2009), Rêgo (2009), Bianconi e Yoshino (2013) e Paixão (2015). Com exceção do trabalho de Rêgo (2009), que busca estimar índices nacionais, os demais trabalhos brasileiros centram-se em uma única cidade. Do ponto de vista da abrangência temporal, os trabalhos de Rozenbaum (2009) e Paixão (2015) são os mais extensos, estimando índices de preços para apartamentos, no município do Rio de Janeiro, entre 1997 e 2007, e Belo Horizonte, entre 1995 e 2003, respectivamente.

Os trabalhos citados, tanto na literatura internacional quanto na nacional, analisam o mercado imobiliário como sendo único. Porém, Grigsby, Baratz e Maclennan (1987', apud Megbolube, Hoek-Smith e Linneman, 1996) e Zietz, Zietz e Sirmans (2008) argumentam que o mercado imobiliário é segmentado. A determinação do preço do imóvel varia de acordo como o segmento de mercado, isto é, do perfil de renda e da capacidade de acessar o crédito imobiliário por parte das famílias. A metodologia econométrica para lidar com a segmentação do mercado é a regressão quantílica, em que cada quantil da distribuição representa um segmento de mercado. Desse modo, pode-se supor que a dinâmica dos preços imobiliários varia de acordo com o segmento. Recentemente surgiram na literatura internacional alguns estudos estimando índice de preços nos quantis, como Els e Fintel (2010), Barthélémy, Rosiers e Baroni (2013), Deng, McMillen e Sing (2012), Coulson e McMillen (2007) e McMillen (2014)2. Para o Brasil, até o presente momento ${ }^{3}$, ainda não há estudos estimando índices de preços quantílicos para imóveis. Furtado (2007) utilizou um modelo hedônico-quantílico para uma análise cross-section do mercado imobiliário de Belo Horizonte.

O presente estudo busca preencher essa lacuna da literatura nacional, aplicando a regressão quantílica para estimar índice de preços para imóveis. Para isso, utilizaremos uma base de dados contendo informações sobre apartamentos transacionados no município de Belo Horizonte, entre 1995 e 2012. A análise será feita conjugando a literatura do mercado imobiliário segmentado com a discussão em torno dos diferentes métodos de estimação de índice de preços hedônicos para imóveis. A partir dessa discussão os objetivos do trabalho são:

1 GRIGSBY, W.; BARATZ, M.; MACLENNAN, D. The dynamics of neighbourhood change and decline. Oxford: Pergamon, 1987. $76 \mathrm{p}$.

2 McMillen (2014) mensurou índices de preços por quantis a partir de uma regressão geograficamente ponderada.

3 Este artigo foi submetido em 2016. 
a) Avaliar se houve alguma diferença no padrão de valorização imobiliária nos diferentes segmentos do mercado imobiliário;

b) Apresentar uma pequena discussão sobre os possíveis fatores da conjuntura econômica que possam ter afetado a valorização imobiliária observada no período analisado.

Além de responder as questões acima, o artigo terá como contribuição analisar o mercado imobiliário em um período extenso, 1995-2012, uma vez que as contribuições acadêmicas existentes aplicadas a mercados brasileiros cobrem um período menor. Por fim, a discussão sobre o método é pertinente em uma realidade onde não existe um índice oficial de preços de imóveis, e, com exceção do trabalho de Rozenbaum (2009), a literatura acadêmica não tem discutido a fundo essa questão.

O texto que se segue está organizado em três seções. Após esta Introdução, a segunda seção discute a mensuração de índice de preços a partir do modelo de preços hedônicos, sob a perspectiva do mercado imobiliário segmentado. Nessa discussão, justifica-se a mensuração de índice de preços hedônicos-quantílicos para imóveis. A terceira seção apresenta a base de dados, o modelo a ser estimado e os resultados.

\section{2 Índice de preços hedônicos nos quantis}

\section{1 Índice de preços para imóveis}

O imóvel pertence à classe dos "bens diferenciados" assim caracterizados porque cada unidade/modelo se diferencia das demais pela composição dos atributos. A literatura de índice de preços, portanto, buscou encontrar uma forma de medir a variação de preços que controlasse as diferentes composições de atributos. Hill (2013) acrescenta que o imóvel é um tipo especial de bem durável, uma vez que cada unidade do imóvel é distinta das demais. No mercado de imóveis unifamiliares (casas) esse caráter peculiar do imóvel é evidente. Mas mesmo no mercado de residências multifamiliares (apartamentos e condomínios) essa idiossincrasia se aplica porque mesmo apartamentos no mesmo prédio estão localizados em posições diferentes o que embute, por si só, um tipo de diferenciação. Somado a isso, cada unidade imobiliária é vendida de forma inconstante no tempo, tornando praticamente impossível à construção de uma cesta 
de unidades imobiliárias. Por fim, os atributos que constituem um imóvel são tanto físicos (características de cada unidade) quanto espaciais (característica da localização).

A literatura trabalha com três tipos de métodos para mensurar índice de preços para imóveis. O método mais simples é o estratificado. Por essa metodologia, o índice de preço é mensurado para estratos de imóveis. Em geral, definem-se os estratos e calcula-se a trajetória do valor da mediana de cada estrato. $O$ estrato pode ser uma característica ou combinações de características dos imóveis. A maior crítica a esse tipo de metodologia é que o imóvel é composto por um conjunto grande de atributos, ou seja, limitar os estratos a um ou a uma combinação de dois ou mais atributos acaba por gerar índices viesados (Diewert, 2009). Existe ainda um trade off na medida em que se adicionam novos atributos, menos observações tende a se ter para cada estrato, o que pode gerar problemas na estimação. Por isso, a literatura passou a trabalhar com índices estimados por modelos econométricos.

O método das vendas repetidas (MVR), desenvolvido por Bailey, Muth e Nourse (1963), é uma alternativa ao método de estratificação. Nesse caso, utiliza-se uma amostra composta apenas por unidades imobiliárias que foram vendidas e posteriormente revendidas. Ao limitar a amostra a unidades que foram transacionados em dois pontos do tempo, o MVR está tentando controlar a valorização de preço pelo diferencial das características. A partir dessa amostra, utiliza-se um modelo de regressão no qual a variável dependente é o preço, e as variáveis independentes são os períodos de venda e o período da revenda. A partir dos parâmetros estimados calcula-se o índice de preços.

Embora o MVR seja mais robusto do que os métodos estratificados, alguns problemas persistem. Primeiramente, limitar a amostra a revendas não resolve por completo a questão da diferenciação do bem imóvel. Uma mesma unidade imobiliária está sujeita a depreciação, reformas, melhoramentos etc., no decorrer do tempo (Diewert, 2009; Hill, 2013). Ou seja, o MVR resolve parcialmente a questão da diferenciação, estando, entretanto, sujeito ainda ao viés de variável omitida. Por fim, Diewert (2009) aponta que limitar a amostra a revendas pode levar ao problema de insuficiência da amostra, dependendo das características locais do mercado imobiliário. Nos EUA, onde a rotação do estoque imobiliário é frequente, o MVR é muito utilizado. No restante do mundo as vendas e revendas de imóveis são menos frequentes, tornando o MVR mais limitado (Diewert, 2009). 
O modelo de preços hedônicos (MPH) parte da ideia de que o preço do bem é determinado em função das características. $O$ modelo é aplicado desde a década de 1920, com a contribuição de Waugh (1928). Posteriormente, Court (1939) e Griliches (1961) aplicaram o MPH para gerar índice de preços para automóveis. Em seguida, a aplicação do MPH para gerar índice de preços se ampiou para outros mercados de bens duráveis e para o mercado imobiliário.

Rosen (1974) formulou um modelo abstrato para a formação de preços de um produto diferenciado. Partindo-se da hipótese hedônica de que um produto é valorizado pela utilidade contida em cada um dos seus atributos, Rosen (1974) definiu a função hedônica de preços da seguinte maneira:

$$
p(z)=p\left(z_{1}, z_{2}, \ldots, z_{n}\right)
$$

onde $p$ é o preço do bem, e $z_{1}$, a i-ésima característica do bem. No caso, cada unidade do produto é definida por um determinado pacote de características, e, num mercado de produtos diferenciados, existem variados pacotes de características disponíveis. Em um mercado competitivo, em que se encontram consumidores e produtores para cada característica, o preço implícito da i-ésima característica é dado pela primeira derivada da função (1) em direção à característica $i$ :

$$
p_{i}=\frac{\partial p}{\partial z_{i}}
$$

Pelo modelo de Rosen (1974), o preço implícito é resultante de uma interação de mercado. Portanto, esse preço é interpretado como o quanto o preço de mercado do bem varia a partir de um acréscimo marginal na i-ésima característica. Para fins de cálculo de índices de preços hedônicos, o preço implícito é a forma de controlar a variação do preço pelas diferenças nas características de cada unidade do bem. Segundo Griliches (1971), a utilização da metodologia hedônica para mensurar índice de preços é uma forma de estimar a variação "pura" do preço do bem composto, uma vez que a partir da regressão hedônica pode-se expurgar da variação temporal de preços os efeitos da mudança nas características (qualidade) do bem. 


\subsection{Métodos hedônicos para estimar índice de preços}

Existem diversas formas de estimar índice de preços a partir do modelo de preços hedônicos (Triplett, 2004; Hill, 2013). A estimação do índice hedônico pode se dar por meio de regressões com dummy de tempo ou por um conjunto de regressões num único ponto do tempo. Os modelos utilizando regressões com dummy de tempo foram denominados por Triplett (2004) de métodos hedônicos time-dummy (TD). Em sua forma mais simples, o método TD requer uma única regressão para todo o período com uma dummy para cada ponto no tempo. Em geral, a categoria básica é o período inicial. A regressão TD está resumida a seguir:

$$
\ln (p)=z \beta+D \delta+\varepsilon
$$

sendo $\ln (p)$ o logaritmo natural do preço do imóvel, $z$ o conjunto das $n$ características do bem, $\beta$ o preço implícito estimado pela regressão, $D$ a dummy para cada ponto no tempo, $\delta$ o parâmetro estimado para cada dummy de tempo e $\varepsilon$ o resíduo aleatório da regressão. $O$ índice de preço é calculado a partir do parâmetro estimado para a dummy de tempo, conforme a expressão abaixo:

$$
I P_{t}=\exp \left(\delta_{t}\right)
$$

A maior crítica ao método TD, de regressão única, é esse ter como hipótese implícita de que os preços sombras das características são constantes no tempo. Para Triplett (2004) o método TD não se aplica a mercados sujeitos a constantes mudanças tecnológicas. Hill (2013) argumenta que no caso dos bens imóveis essas inovações tecnológicas são menos dinâmicas, mas para períodos suficientemente longos pode se supor que mudanças nas condições de oferta e da demanda imobiliária farão com que os preços implícitos das características se alterem. Para dar conta dessa realidade, a saída é utilizar um conjunto de regressões TD para períodos de tempo adjacentes - adjacent-period-time-dummy (APTD) (Triplett, 2004; Hill, 2013). Na prática, o APTD consiste em estimar a regressão (4) para cada subperíodo especificado.

Os métodos hedônicos por regressões cross-section utilizam os preços implícitos estimados pela regressão para imputar dados de observações 
não disponíveis. A partir desses métodos é possível calcular índices de preços superlativos ${ }^{4}$. Essas metodologias partem de um conjunto de regressões para pontos de tempo específicos:

$$
\ln (p)=Z \beta+\varepsilon
$$

O método da imputação hedônica (MIH) consiste em criar, através de um conjunto de regressões (5), uma cesta de imóveis em dois períodos distintos $^{5} t_{0}$ e $t_{1}$. A partir dos parâmetros estimados para uma regressão em $t_{0}$ estima-se o preço que cada imóvel transacionado em $t_{1}$ teria caso fosse transacionado em $t_{0}$. De maneira análoga, com a regressão em $t_{1}$ pode-se estimar o preço que cada imóvel transacionado em $t_{0}$ teria caso fosse transacionado no período seguinte. Em princípio, a valorização de cada unidade é a relação entre o preço observado e o seu contrafactual - estimado por regressão. Todavia, Hill e Melser (2008) argumentam que, no caso dos imóveis, o ideal é utilizar o preço estimado pela regressão também no período em que o imóvel foi transacionado (dupla imputação), uma vez que esse procedimento minimiza o viés da variável omitida.

Os índices obtidos a partir do MIH correspondem à média geométrica da variação de preço de cada observação. Desse modo, quando $t_{0}$ é o período básico tem-se um índice geométrico de Laspeyres (IGL). Quando $t_{1}$ é o período base tem-se o índice geométrico de Paasche (IGP). A média geométrica entre IGL e IGP é o índice de preços Törnqvist (IPT). Hill (2013) recomenda a utilização do IPT por se tratar de um índice superlativo.

O outro método cross-section é o método hedônico das características (MHC) (Hill, 2013). Esse método consiste em gerar uma regressão para cada período e utilizar as características médias dos imóveis para realizar as imputações. Computacionalmente o método consiste em imputar a característica média dos imóveis de $t_{0}$ nas regressões de $t_{0} \mathrm{e} t_{1}$, obtendo um índice de Laspeyres. E, analogamente, imputa-se as características médias de $t_{1}$ nas regressões para $t_{0}$ e $t_{1}$, obtendo um índice de Paasche. Hill (2013) recomenda utilizar o índice superlativo de Fisher - a raiz quadrada do produto entre o índice de Laspeyres e Paasche - como índice de preço do MHC.

4 Os índices superlativos incorporam o efeito substituição, não havendo sub ou sobre-estimação. Para mais detalhes sobre esses métodos, ver Hill (2013).

5 No caso $t_{0}$ e $t_{1}$ representam períodos adjacentes. Para um período longo, $t_{0}$ representa todos os períodos anteriores, e $t_{1}$ todos os períodos posteriores. 
Dentre os índices mensurados a partir de regressões com dummy de tempo, o APTD é superior ao TD, por não depender da hipótese de estabilidade temporal dos preços sombra (Triplett, 2004; Hill, 2013). Frente aos índices das regressões cross-section, os métodos TD e APTD têm como vantagens serem de mais simples aplicação (parcimônia) e a estimação dos desvios padrões serem diretas. Porém, os índices estimados pelo $\mathrm{MIH} \mathrm{e}$ $\mathrm{MHC}$ apresentam como vantagem poderem incorporar fórmulas conhecidas de índice de preços como Laspeyres, Paasche, Fisher e Törnqvist.

$\mathrm{Na}$ comparação entre os métodos cross-section, temos que para o caso dos bens imóveis a aplicação do MHC, por ser uma imputação pelo imóvel típico, não é trivial. A localização é um dos fatores determinantes na formação do preço dos imóveis e não se tem como mensurar uma localização típica por estatísticas como média ou mediana (Hill, 2013). Portanto, para aplicar o MHC para o caso dos bens imóveis é preciso buscar alguma metodologia para lidar com a questão da localização. Nesse sentido, o MIH é o método cross-section mais adequado para a nossa base de dados.

\subsection{A segmentação do mercado imobiliário}

O modelo hedônico tradicional de Rosen (1974) parte do paradigma do agente representativo, supondo que a estrutura de preferências é única para todos os consumidores, e que, sendo assim, os proprietários dos imóveis, tanto dos segmentos superiores quanto dos segmentos inferiores, só se diferenciam pela restrição orçamentárias aos quais estão sujeitos (Zietz, Zietz; e Sirmans, 2008). Nesse caso, o preço implícito de cada característica (2) seria único, e o método dos mínimos quadrados ordinários seria adequado para estimar os preços implícitos das características dos imóveis. Porém, estudos comparando resultados de várias aplicações de modelo de preços hedônicos para o mercado imobiliário americano encontraram instabilidades nos valores dos parâmetros estimados, na direção do efeito marginal e na significância estatística desses parâmetros (Zietz, Zietz e Sirmans, 2008). Segundo os autores, essa realidade pode ser derivada do fato de que a determinação dos preços dos imóveis varia de acordo com a posição que cada imóvel ocupa na distribuição dos preços imobiliários. 
Em uma perspectiva teórica, Grigsby, Baratz e Maclennan (19876, apud Megbolube, ; Hoek-Smith e; Linneman, 1996) argumentam que o mercado imobiliário, para uma dada cidade, é na verdade um conjunto de submercados ${ }^{7}$. Segundo os autores, um submercado imobiliário é caracterizado por uma vizinhança (bairro) onde os imóveis ali localizados podem ser considerados substitutos quase perfeitos. Desse modo, em cada submercado o ambiente construído e o perfil social dos habitantes tendem a ser homogêneos.

No modelo de Grigsby, Baratz e Maclennan (1987, apud Megbolugbe, Hoek-Smith e Linneman, 1996), as famílias mais abastadas buscam residir em moradias de alto padrão em localidades dotadas de infraestrutura e de uma rede de serviços (públicos e privados) tidos como adequadas. Aumentos na renda dessas famílias fazem com que essas busquem residências de melhor padrão em uma nova localização (novo submercado), impulsionando o mercado de construção civil ${ }^{8}$.

Do ponto de vista da dinâmica imobiliária, a migração das famílias abastadas para novas localizações altera a configuração dos demais submercados, uma vez que famílias um pouco menos abastadas tendem a habitar as localizações preteridas pelas famílias de perfil socioeconômico superior. Como resultado, tem-se uma estrutura urbana segregada, na qual o mercado imobiliário é segmentado, e o paradigma do agente representativo único se mostra limitado para explicar o seu funcionamento (Zietz; Zietz; Sirmans, 2008). Nesse caso, o preço implícito, dado pela equação 2 , varia em cada submercado. Sendo o segmento do mercado denotado por (q), pode-se reescrever (2) da seguinte forma:

$$
p_{i, q}=\left(\frac{\partial p}{\partial z_{i}}\right)_{q}
$$

Nesse caso, as estimações por mínimos quadrados ordinários não são adequadas, sendo o método das regressões quantílicas o mais apropriado para lidar com a segmentação de mercado?.

6 GRIGSBY, W.; BARATZ, M.; MACLENNAN, D. The Dynamics of Neighbourhood Change and Decline. Oxford: Pergamon, 1987, 76 p.

7 Agradecemos a um(a) parecerista anônimo(a) pela sugestão de incluir a contribuição de Grigsby et al. (1987).

8 O financiamento imobiliário cumpre papel relevante na segmentação do mercado imobiliário. 9 Almeida, Monte-Mór e Amaral (2017) empregando fuzzy clustering analysis ao mercado imobiliário de Belo Horizonte encontraram evidências de que esse é segmentado. 


\subsection{A regressão quantílica}

Um quantil é uma divisão de um conjunto ordenado de observações de uma variável (y) em g partes iguais. A mediana divide as observações ordenadas em duas partes, o quartil em quatro partes, o quintil em cinco partes, e assim por diante. O quantil, portanto, é o caso geral (Koenker; Hallock, 2001). A regressão quantílica estende a ideia dos quantis para estimação de função de quantis condicionais, isto é, modelos em que os quantis da distribuição condicional da variável resposta (y) são expressos em função das suas covariadas observadas (x's) (Koenker; Hallock, 2001). Existem três vantagens em utilizar a regressão quantílica (Cameron; Trivedi, 2005):

a) Os parâmetros estimados são robustos, mesmo na presença de outliers;

b) Permite uma caracterização mais rica dos dados, ou seja, permite avaliar se a resposta da variável dependente $(y)$ em relação às mudanças nos valores das variáveis independentes $\left(x^{\prime} s\right)$ se altera nos diferentes pontos da distribuição condicional de $y$; e

c) Independe das hipóteses de homocedasticidade e normalidade dos resíduos.

A regressão quantílica parte de uma relação linear entre a variável dependente e as variáveis independentes, na qual tanto o intercepto quanto as inclinações variam nos quantis da distribuição condicional da variável dependente (Cameron; Trivedi, 2010), como na expressão:

$$
y_{i}=x_{i}^{\prime} \beta_{q}+u_{i}
$$

sendo $y$ a variável dependente, $x$ um conjunto de variáveis independentes (covariadas), $\beta$ os parâmetros a serem estimados, $q$ o quantil da distribuição condicional de $y$ e $u$ o termo do erro aleatório. A estimação dos parâmetros nos quantis $\left(\hat{\beta}_{q}\right)$ corresponde a minimizar uma função objetivo da soma ponderada dos desvios absolutos, como na expressão a seguir:

$$
\min _{\beta_{q}} Q R=\min _{\beta_{q}} \sum_{i: y_{i} \geq x_{i}^{\prime} \beta}^{N} q\left|y_{i}-x_{i}^{\prime} \beta_{q}\right|+\sum_{i: y_{i \leq x_{i}^{\prime} \beta}}^{N}(1-q)\left|y_{i}-x_{i}^{\prime} \beta_{q}\right|
$$

na qual $Q R$ significa regressão quantílica (quantile regression).

A função quantílica (8) não é passível de diferenciação, porém seus parâmetros podem ser estimados a partir de métodos de programação linear (Cameron; Trivedi, 2010; Buchinsky, 1998). O método simplex é o mais 
utilizado, pois permite encontrar uma solução a partir de um número finito de interações (Cameron; Trivedi, 2010). A escolha do quantil (q) da estimação corresponde a impor um peso para os desvios $\left(y_{i}-x_{i}^{\prime} \beta\right)$ positivos e negativos. Por exemplo, a estimação da regressão para o primeiro quartil $(q=0,25)$ consiste em atribuir peso de $25 \%$ para os desvios positivos $\left(y \geq x^{\prime} \beta\right)$, e peso $75 \%$ para os desvios negativos $\left(y \leq x^{\prime} \beta\right)$.

O parâmetro estimado pela regressão quantílica é interpretado como a resposta da variável dependente $(y)$ no quantil condicional $q$ decorrente de uma variação marginal da j-ésima variável independente $\left(x_{j}\right)$, como na expressão:

$$
\hat{\beta}_{q}=\frac{\partial\left(Q R_{q}\right)}{\partial x_{j}}
$$

Essa interpretação para (9) é válida apenas para variações infinitesimais das covariadas. Para variações de maiores magnitudes, entretanto, poderá haver mudanças no quantil condicional da observação de y (Buchinsky, 1998; Cameron; Triveldi, 2010). Os desvios padrões dos parâmetros estimados na regressão quantílica são obtidos a partir da metodologia bootstrap (Cameron; Trivedi, 2010).

\section{Resultados}

\subsection{Base de dados}

A base de dados utilizada foi proveniente do Imposto de Transmissão de Bens Imóveis "Inter-vivos" (ITBI) da Prefeitura Municipal de Belo Horizonte $(\mathrm{PBH})$. Para o período 1995-2003 os dados foram fornecidos pela Secretária Municipal de Fazenda (SEFAZ) da PBH. Os dados para período 20042012 foram fornecidos pela Fundação Instituto de Pesquisas Econômicas, Administrativas e Contábeis de Minas Gerais (IPEAD) da Universidade Federal de Minas Gerais (UFMG). Como toda transação imobiliária para ser efetivada deve ter o ITBI quitado, a base de dados desse imposto contempla o universo das transações imobiliárias no mercado formal. Nesse quesito, essa base de dados é mais abrangente do que aquelas provenientes dos dados de financiamento ou anúncio de imóveis. Contudo, o ITBI não cobre o mercado informal de imóveis, que abarca uma parcela significativa 
do mercado de habitações no Brasil e na América Latina ${ }^{10}$ (Abramo, 2008), a base de dados do ITBI acaba por sub-representar a população de mais baixa renda ${ }^{11}$. Porém, nem os dados provenientes dos financiamentos imobiliários nem os provenientes de anúncios de agentes do mercado (imobiliárias e corretores) contemplam o mercado informal. Apenas pesquisas domiciliares, como as pesquisas de orçamentos familiares ou a Pesquisa Nacional por Amostras de Domicílio (PNAD), abrangem esse mercado. Todavia, essas pesquisas não são desenhadas com objetivo de se ter uma amostra representativa de transações ou valores de imóveis, sendo limitadas para a construção de índice de preços. Desse modo, a base de dados do ITBI é uma das mais completas para estudos do mercado imobiliário e construção de índice de preços para imóveis no Brasil.

O ITBI fornece as seguintes informações sobre o imóvel: valor, dimensão da área privativa, padrão de acabamento, idade e bairro onde se localiza o imóvel. O valor é o preço em Reais constante na guia do ITBI, que corresponde ao maior entre o avaliado e o declarado pelo comprador do imóvel. A área privativa é medida em metros quadrados. O padrão de acabamento é derivado de uma classificação que a PBH faz dos imóveis, classificando-os em cinco categorias: luxo, alto, normal, baixo e popular. A localização adotada pela PBH é o bairro, sendo que em Belo Horizonte existem 270 bairros. Para os fins deste estudo, utilizamos o conceito de Área de Ponderação (AP), em número de 62, que corresponde a uma aglomeração de bairros. A idade corresponde à diferença entre o ano de inauguração do móvel e o ano de sua venda. O período da análise vai de 1995 a 2002. O período inicial foi determinado pela disponibilidade de dados pela $\mathrm{PBH}$. A partir da Constituição de 1988, o ITBI passou a ser recolhido pelas prefeituras municipais. Porém, nos contatos com a Secretária de Fazenda (SEFAZ) da PBH, foi acordado que só era possível disponibilizar os dados a partir de 1995.

A Tabela 1 apresenta os valores médios e medianos para preço, área e idade dos imóveis por ano. Nota-se que para o período entre 1995 e 2003 os preços médios se afastaram em grande magnitude dos preços medianos, assim como os coeficientes de variação para o preço foram altos. Isso pode ser reflexo de problemas de transcrição de dados, comum nas bases do ITBI (Gonzalez, 1997a). Pelos preços medianos, o valor do imóvel passou

10 Segundo Cyrillo (2011), em 2014, cerca de $22 \%$ da população belo-horizontina vivia em vilas, favelas e conjuntos habitacionais que ocupavam $5 \%$ do território do município.

11 Agradeço a um(a) parecerista anônimo(a) por chamar a atenção para esse ponto. 
de $\mathrm{R} \$ 48.041,09$, em 1995, para $\mathrm{R} \$ 274.938,80$, em 2012, valorizando, em termos nominais, $472,30 \%$ nesses 17 anos. A área mediana dos apartamentos oscilou entre 94,00 e $113,53 \mathrm{~m}^{2}$ no período, enquanto a idade mediana ficou entre 5 e 10 anos.

Tabela 1 Número de observações e valor médio, mediano e coeficiente de variação para preço nominal, área e idade dos apartamentos transacionados em Belo Horizonte, 1995-2012, por ano

\begin{tabular}{|c|c|c|c|c|c|c|c|c|c|c|}
\hline \multirow[t]{2}{*}{ Ano } & \multirow{2}{*}{$\begin{array}{r}\text { Número } \\
\text { de } \\
\text { obser- } \\
\text { vações }\end{array}$} & \multicolumn{3}{|r|}{ Preço } & \multicolumn{3}{|r|}{ Área } & \multicolumn{3}{|r|}{ Idade } \\
\hline & & Média & $\begin{array}{r}\text { Medi- } \\
\text { ana }\end{array}$ & $\begin{array}{r}\text { Coefici- } \\
\text { ente de } \\
\text { variação }\end{array}$ & Média & $\begin{array}{r}\text { Medi- } \\
\text { ana }\end{array}$ & $\begin{array}{c}\text { Coefici- } \\
\text { ente de } \\
\text { variação }\end{array}$ & Média & $\begin{array}{r}\text { Medi- } \\
\text { ana }\end{array}$ & $\begin{array}{l}\text { Coefici- } \\
\text { ente de } \\
\text { variação }\end{array}$ \\
\hline 1995 & 11.854 & $199.538,50$ & $48.041,09$ & 18,97 & 130,21 & 113,53 & 0,63 & 10 & 6 & 1,05 \\
\hline 1996 & 13.245 & $130.307,30$ & $50.000,00$ & 27,23 & 127,65 & 108,64 & 0,74 & 10 & 6 & 1,02 \\
\hline 1997 & 16.002 & $117.998,80$ & $50.429,12$ & 39,03 & 125,36 & 107,05 & 0,62 & 11 & 9 & 0,94 \\
\hline 1998 & 15.175 & $457.919,00$ & $58.000,00$ & 77,21 & 135,14 & 116,00 & 0,93 & 11 & 6 & 1,02 \\
\hline 1999 & 15.762 & $86.181,77$ & $55.073,14$ & 7,81 & 129,72 & 109,26 & 0,81 & 10 & 5 & 1,08 \\
\hline 2000 & 17.103 & $111.470,20$ & $54.900,00$ & 23,61 & 127,42 & 107,30 & 0,82 & 10 & 5 & 1,08 \\
\hline 2001 & 16.896 & $80.594,81$ & $53.000,00$ & 1,26 & 130,40 & 103,56 & 3,09 & 10 & 5 & 1,18 \\
\hline 2002 & 22.128 & $1.811 .372,00$ & $58.690,76$ & 137,29 & 128,39 & 103,29 & 0,86 & 10 & 5 & 1,08 \\
\hline 2003 & 19.645 & $97.807,81$ & $59.850,56$ & 5,18 & 129,80 & 102,20 & 0,80 & 12 & 7 & 1,00 \\
\hline 2004 & 18.179 & $95.376,85$ & $60.000,00$ & 1,40 & 125,70 & 102,00 & 0,88 & 13 & 8 & 0,95 \\
\hline 2005 & 20.193 & $97.229,25$ & $61.105,11$ & 1,26 & 121,74 & 98,63 & 0,77 & 14 & 10 & 0,88 \\
\hline 2006 & 19.159 & $112.950,40$ & $70.000,00$ & 1,42 & 125,21 & 101,88 & 1,00 & 14 & 10 & 0,88 \\
\hline 2007 & 19.939 & $129.282,20$ & $82.324,41$ & 1,15 & 122,58 & 102,95 & 0,67 & 14 & 10 & 0,88 \\
\hline 2008 & 19.479 & $160.223,90$ & $100.000,00$ & 1,17 & 125,83 & 101,38 & 2,99 & 14 & 10 & 0,86 \\
\hline 2009 & 18.584 & $193.481,50$ & $130.000,00$ & 1,14 & 124,74 & 98,66 & 1,36 & 14 & 10 & 0,93 \\
\hline 2010 & 21.487 & $234.514,30$ & $160.061,60$ & 1,07 & 116,47 & 94,00 & 0,77 & 12 & 8 & 1,08 \\
\hline 2011 & 19.592 & $308.460,00$ & $219.999,90$ & 0,99 & 121,25 & 98,00 & 0,69 & 12 & 7 & 1,14 \\
\hline 2012 & 18.710 & $379.685,50$ & $274.938,80$ & 0,97 & 127,23 & 107,08 & 0,70 & 12 & 7 & 1,15 \\
\hline
\end{tabular}

Fonte: Elaboração própria a partir dos dados do ITBI fornecidos pela PBH e IPEAD UFMG.

O Gráfico 1 apresenta a evolução do preço dos imóveis. Nota-se que os imóveis na parte inferior da distribuição dos valores de preço (percentil 10 e percentil 25) obtiveram valorização nominal acima da mediana no período (550,0\% e $524,8 \%$, respectivamente), enquanto os imóveis na parte superior da distribuição dos valores de preço (percentil 75 e percentil 90) 
valorizaram no período a uma taxa abaixo da mediana (456,9\% e 465,0\%, respectivamente).

Gráfico 1 Evolução dos preços nominais dos apartamentos por quantil, Belo Horizonte $-1995-2012$

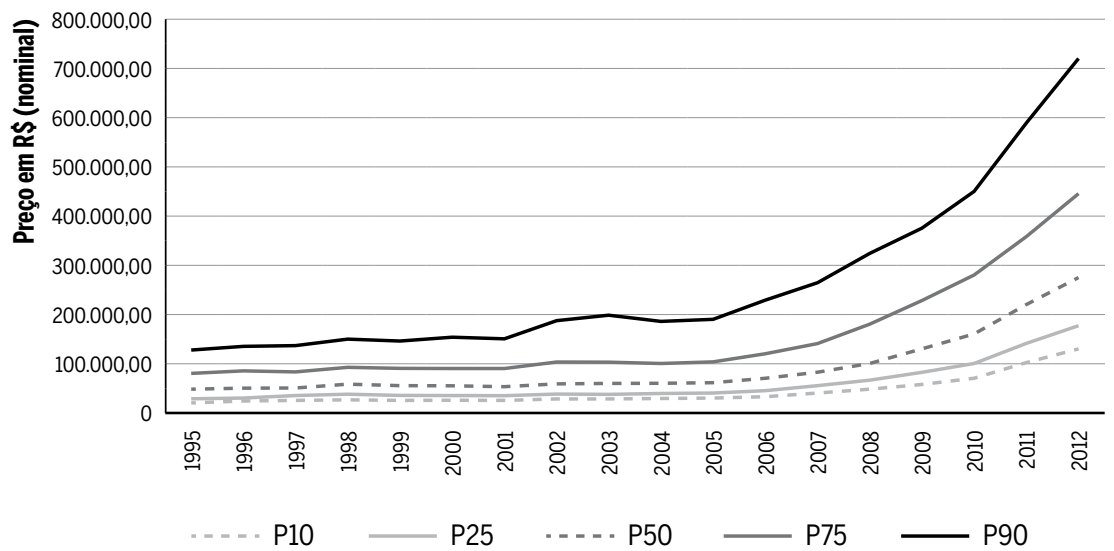

Fonte: Elaboração própria a partir dos dados do ITBI fornecidos pela PBH e IPEAD UFMG.

\subsection{0 modelo estimado}

O objetivo deste estudo é estimar regressões quantílicas para construir índice de preços para apartamentos em Belo Horizonte entre 1995 e 2012. Com isso aplicaremos essa técnica (equação 10) para os métodos hedônicos descritos na seção 2.2. Foram estimados, como definido na seção 2.2, índices de preços hedônicos-quantílicos a partir dos métodos APTD e $\mathrm{MIH}$. Como os resultados do APTD mostraram-se mais estáveis, utilizaremos esse método no restante do texto ${ }^{12}$.

\subsubsection{Variáveis utilizadas}

A formação do preço dos imóveis é determinada pelas características físicas (intrínsecas) e pelas características extrínsecas, ou seja, aquelas rela12 Os resultados dos índices e variações de preços do $\mathrm{MIH}$, assim como as saídas das regressões do APTD, encontram-se com o editor. 
cionadas à localização do imóvel. As variáveis intrínsecas foram definidas a partir das disponíveis na base de dados do ITBI: padrão de acabamento, área e idade. Foi criada uma dummy para cada padrão de acabamento: popular, baixo, normal (categoria básica), bom e luxo. A área foi medida de forma linear e ao quadrado, o mesmo procedimento adotado para idade. A inclusão do quadrado dessas variáveis deve-se ao pequeno número de variáveis intrínsecas contidas na base do ITBI. Por exemplo, informações como número de vaga de garagem, presença de playground ou outros serviços condominiais, andar do apartamento ou número de unidades habitacionais contidas nos condomínios são relevantes para a formação de preços no merca do imobiliário, mas não estão presentes na base de dados do ITBI. Por esse motivo, optou-se por incluir o quadrado da área do imóvel.

No caso da idade a não linearidade é justificada, ainda, por essa ser uma proxy imperfeita para a depreciação do imóvel (Goodman; Thibodeau, 1995). Os bens imóveis podem sofrer reformas, modernizações ou melhoramentos ao longo do tempo, atenuando ou mesmo revertendo o efeito da depreciação. Como resultado, dois imóveis com a mesma idade podem ter condições de uso bastante distintas.

As variáveis extrínsecas relacionam o imóvel à sua localização no espaço urbano. A nova economia urbana (NEU), derivada das contribuições de Alonso (1964) e Muth (1969), desenvolveu-se a partir do insight teórico de Von Thünen (1826) sobre a relevância da localização como entidade econômica. ${ }^{13}$ Para a NEU, o espaço urbano é estruturado a partir de um único centro da cidade $\left(\mathrm{CBD}^{14}\right)$ onde se concentram os empregos e os serviços urbanos. Desse modo, quanto mais distante a localização de um terreno em relação ao CBD menor será o preço da terra urbana, dado que maiores são os custos de transporte (custos monetários e custo de oportunidade) nos deslocamentos cotidianos. Portanto, pela teoria da economia urbana o preço do imóvel tende a decrescer na medida em que a sua localização se torna mais afastada do CBD.

Posteriormente a literatura incluiu subcentros (Fujita; Ogawa,1982) e as amenidades urbanas (Freeman, 1979; Brueckner, Thisse e Zenou, 1999). Algumas amenidades são positivas, como a existência de parques, restaurantes, escolas de qualidade, entre outras. Por outro lado, algumas ameni-

13 Para melhor entendimento sobre o surgimento da economia urbana ver Abramo (2001). 14 CBD é abreviação para Central Business District. 
dades são tidas como negativas (desamenidades), como ar poluído, crimes, presença de cemitérios e aterros sanitários etc.

Embora tanto a distância do centro (e a subcentros) e as amenidades urbanas exerçam importante papel na formação dos preços dos imóveis, optou-se por estimar o modelo hedônico proposto por Hill (2013) com efeitos fixos para localização. Não existe um modelo teórico que estabeleça de forma exaustiva as amenidades que de fato afetam o preço dos imóveis. Somadas a isso, muitas amenidades urbanas são medidas em uma periodicidade específica (caso das medidas por Censo Demográfico) outras, sequer, têm periodicidade de medição (estudos especiais, índices calculados pelo poder local etc.).

Como analisado anteriormente, recentemente existe uma discussão sobre até que ponto o modelo monocêntrico é o mais adequado, e caso não seja, levanta-se o problema de como identificar não só os subcentros, mas a dinâmica de surgimentos e desaparecimentos desses. Por isso, julgamos mais apropriado inserir a localização a partir de uma dummy para as Áreas de Ponderação (AP) do município de Belo Horizonte (BH), sendo a AP Savassi a categoria básica. Existem 62 APs em BH sendo que essa dummy acaba absorvendo tanto o conjunto de amenidades/desamenidades das localizações quanto a distância em relação ao $\mathrm{CBD}$ e aos subcentros. Por outro lado, trabalhar com a dummy por localização elimina o problema decorrente das defasagens de medida das variáveis ambientais, pois permite que o preço implícito de cada microlocalização da cidade seja estimado a cada nova rodada do modelo, evitando o problema da defasagem e/ou falta de periodicidade da disponibilidade das informações sobre as amenidades urbanas.

O logaritmo do valor do apartamento foi a variável dependente e foram estimadas um total de dezessete regressões hedônicas-quantílicas a partir do método APTD, como descrito:

$$
\ln p_{q}=\left(\beta_{0}+\beta_{1} x_{1}+\beta_{2} x_{2}+\beta_{3} x_{3}+\beta_{4} x_{4}+\beta_{6, i} x_{6, i}+\beta_{7, j} x_{7, j}+\beta_{8} t_{1}+\varepsilon\right)_{q}^{t_{0}, t_{1}}
$$

sendo $p$ o preço do imóvel, $x_{1}$ a área, $x_{2}$ o quadrado da área, $x_{3}$ a idade do imóvel, $x_{4}$ o quadrado da idade, $x_{6, j}$ o i-ésimo acabamento do imóvel, $x_{7, j}$ o imóvel localizado na $\mathrm{AP} j, t_{1}$ o último período do par de anos, e $\varepsilon$ o resíduo aleatório. $O$ sufixo $t_{0}, t_{1}$ indica que a regressão é estimada para cada par de anos, e o sufixo $q$ representa os quantis nos quais o modelo será estimado. 
Os parâmetros a serem estimados são os $\beta$ 's, que correspondem aos preços sombras das características dos imóveis. No caso das variáveis categóricas (padrão de acabamento e localização), é estimado um preço sombra para cada categoria, exceto a básica. Para a dummy de tempo, o preço sombra é a base para o cálculo do índice de preço em determinado quantil:

$$
I P_{t_{1, q}}=\exp \left(\hat{\beta}_{8, q}\right)
$$

No sentido de permitir a comparação com a literatura sobre o tema, o índice de preços será calculado para os quantis 10\%, 25\%, 50\%, 75\% e $90 \%$ da distribuição condicional do preço dos apartamentos, para Belo Horizonte entre 1995 e 2012.

\subsection{Resultados}

A Tabela 2 e o Gráfico 2 apresentam os índices de preços nos quantis estimados pelo método APTD.

Tabela 2 Índice de preços para apartamentos em Belo Horizonte - 1995-2012

Método adjacent-period-time-dummy (APTD) nos quantis

\begin{tabular}{lrrrrrr}
\hline Ano & $\mathbf{Q ( 1 0 \% )}$ & $\mathbf{Q ( 2 5 \% )}$ & $\mathbf{Q ( 5 0 \% )}$ & $\mathbf{Q ( 7 5 \% )}$ & $\mathbf{Q ( 9 0 \% )}$ \\
\hline $\mathbf{1 9 9 5}$ & 1,00 & 1,00 & 1,00 & 1,00 & 1,00 \\
\hline $\mathbf{1 9 9 6}$ & 1,16 & 1,16 & 1,14 & 1,12 & 1,10 \\
\hline $\mathbf{1 9 9 7}$ & 1,23 & 1,23 & 1,22 & 1,21 & 1,20 \\
\hline $\mathbf{1 9 9 8}$ & 1,25 & 1,23 & 1,23 & 1,24 & 1,25 \\
\hline $\mathbf{1 9 9 9}$ & 1,27 & 1,24 & 1,24 & 1,25 & 1,26 \\
\hline $\mathbf{2 0 0 0}$ & 1,35 & 1,30 & 1,29 & 1,29 & 1,29 \\
\hline $\mathbf{2 0 0 1}$ & 1,37 & 1,33 & 1,32 & 1,31 & 1,31 \\
\hline $\mathbf{2 0 0 2}$ & 1,50 & 1,42 & 1,41 & 1,39 & 1,37 \\
\hline $\mathbf{2 0 0 3}$ & 1,55 & 1,48 & 1,46 & 1,45 & 1,46 \\
\hline $\mathbf{2 0 0 4}$ & 1,63 & 1,56 & 1,55 & 1,54 & 1,57 \\
\hline $\mathbf{2 0 0 5}$ & 1,74 & 1,68 & 1,66 & 1,67 & 1,71 \\
\hline $\mathbf{2 0 0 6}$ & 1,94 & 1,86 & 1,87 & 1,89 & 1,95 \\
\hline $\mathbf{2 0 0 7}$ & 2,21 & 2,15 & 2,19 & 2,25 & 2,36 \\
\hline $\mathbf{2 0 0 8}$ & 2,52 & 2,50 & 2,68 & 2,88 & 3,04 \\
\hline & & & & & (continua)
\end{tabular}


Tabela 2 (continuação)

\begin{tabular}{lr|r|r|r|r}
\hline Ano & $\mathbf{Q ( 1 0 \% )}$ & $\mathbf{Q ( 2 5 \% )}$ & $\mathbf{Q ( 5 0 \% )}$ & $\mathbf{Q ( 7 5 \% )}$ & $\mathbf{Q ( 9 0 \% )}$ \\
\hline $\mathbf{2 0 0 9}$ & 3,02 & 3,13 & 3,47 & 3,75 & 3,89 \\
\hline $\mathbf{2 0 1 0}$ & 4,00 & 4,06 & 4,32 & 4,67 & 4,81 \\
\hline $\mathbf{2 0 1 1}$ & 5,19 & 5,20 & 5,44 & 5,76 & 5,81 \\
\hline $\mathbf{2 0 1 2}$ & 6,51 & 6,26 & 6,37 & 6,58 & 6,57 \\
\hline
\end{tabular}

Fonte: Elaboração própria a partir dos dados do ITBI fornecidos pela PBH e IPEAD UFMG.

Os valores finais, ano de 2012 , estimados para os quantis $10 \%, 25 \%, 50 \%$, $75 \%$ e $90 \%$ foram, respectivamente, 6,51, 6,26, 6,37, 6,58 e 6,57. O índice de inflação acumulada para o período foi de $2,90^{15}$ e o da taxa Selic nominal, 15,25 mostrando que os imóveis, para todos os quantis analisados, valorizaram acima da inflação, mas essa valorização ficou abaixo da evolução acumulada da taxa básica de juros da economia. Entre os fatores que influenciaram na demanda por imóveis, o índice acumulado para o aumento da renda nominal dos trabalhadores da Região Metropolitana de Belo Horizonte (RMBH) foi 3,98, e o índice acumulado para o montante do crédito imobiliário no Brasil foi 5,87. Nota-se que a valorização imobiliária em Belo Horizonte, no período analisado, ficou próxima do crescimento do montante do crédito imobiliário no Brasil.

Gráfico 2 Índice de preços para apartamentos nos quantis - Belo Horizonte - 1995-2012 - estimados pelo método APTD

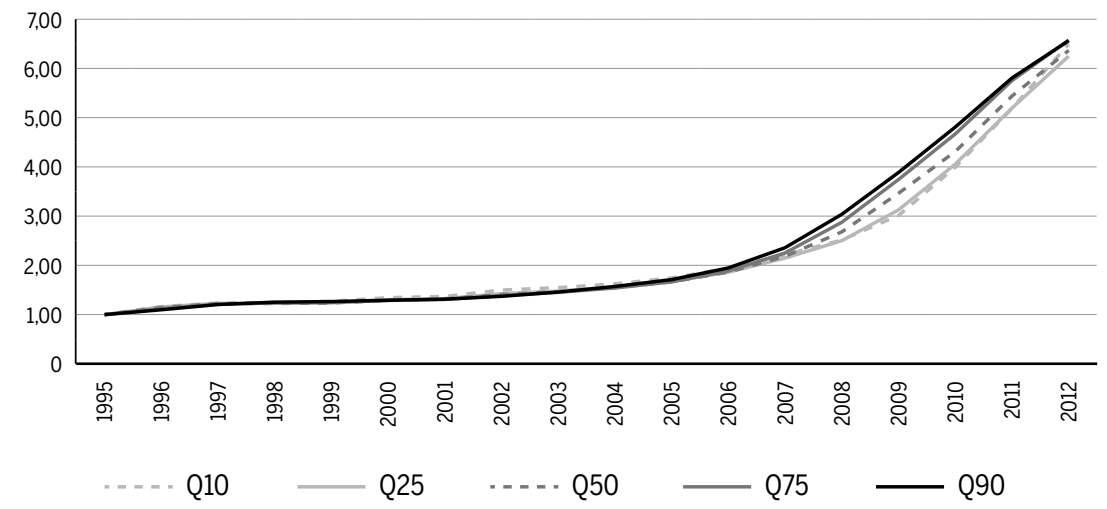

Fonte: Elaboração própria a partir dos dados do ITBI fornecidos pela PBH e IPEAD UFMG.

15 IPCA, PIB e renda nominal média da RMBH (Fonte: IBGE). SELIC e volume de crédito imobiliário (Fonte: Banco Central do Brasil). 
Para o acumulado do período, os imóveis dos segmentos mais altos (Q75\% e Q90\%) foram os que registraram maior valorização. Até 2005, a maior valorização acumulada pertencia ao segmento mais baixo (Q10\%). Entre 2005 e 2010 esse padrão se inverteu, com maior valorização nos quantis superiores (Gráfico 2). No período entre 2010 e 2012, a valorização dos apartamentos dos segmentos mais baixos (Q10\% e Q25\%) e do segmento mediano (0.50\%) foi mais alta, fazendo com que as linhas desses quantis se reaproximassem das linhas dos quantis superiores.

A Tabela 3 e o Gráfico 3 apresentam as valorizações anuais, em termos nominais, dos apartamentos em Belo Horizonte, para os diversos segmentos do mercado imobiliário.

Tabela 3 Taxa de valorização anual dos apartamentos em Belo Horizonte - 1995-2012

Método adjacent-period-time-dummy (APTD) nos quantis

\begin{tabular}{lrrrrrr}
\hline Ano & $\mathbf{Q ( 1 0 \% )}$ & $\mathbf{Q ( 2 5 \% )}$ & $\mathbf{Q ( 5 0 \% )}$ & $\mathbf{Q ( 7 5 \% )}$ & $\mathbf{Q ( 9 0 \% )}$ \\
\hline $\mathbf{1 9 9 6}$ & 16,38 & 15,63 & 14,08 & 11,98 & 9,85 \\
\hline $\mathbf{1 9 9 7}$ & 6,01 & 6,33 & 7,33 & 8,10 & 9,59 \\
\hline $\mathbf{1 9 9 8}$ & 1,20 & 0,18 & 0,09 & 2,31 & 3,98 \\
\hline $\mathbf{1 9 9 9}$ & 1,74 & 0,71 & 0,91 & 0,66 & 1,04 \\
\hline $\mathbf{2 0 0 0}$ & 5,94 & 4,98 & 4,31 & 3,12 & 2,08 \\
\hline $\mathbf{2 0 0 1}$ & 1,79 & 1,82 & 2,15 & 1,73 & 1,70 \\
\hline $\mathbf{2 0 0 2}$ & 9,45 & 7,37 & 6,81 & 5,99 & 4,35 \\
\hline $\mathbf{2 0 0 3}$ & 3,18 & 3,88 & 4,04 & 4,84 & 6,37 \\
\hline $\mathbf{2 0 0 4}$ & 5,06 & 5,58 & 5,71 & 5,98 & 7,91 \\
\hline $\mathbf{2 0 0 5}$ & 7,34 & 7,32 & 7,55 & 8,23 & 8,80 \\
\hline $\mathbf{2 0 0 6}$ & 11,34 & 11,02 & 12,08 & 13,14 & 13,86 \\
\hline $\mathbf{2 0 0 7}$ & 13,98 & 15,54 & 17,16 & 19,51 & 21,15 \\
\hline $\mathbf{2 0 0 8}$ & 13,67 & 16,36 & 22,61 & 27,60 & 28,73 \\
\hline $\mathbf{2 0 0 9}$ & 19,83 & 25,18 & 29,40 & 30,35 & 28,08 \\
\hline $\mathbf{2 0 1 0}$ & 32,54 & 29,70 & 24,47 & 24,64 & 23,70 \\
\hline $\mathbf{2 0 1 1}$ & 29,92 & 28,05 & 26,10 & 23,24 & 20,72 \\
\hline $\mathbf{2 0 1 2}$ & 25,29 & 20,32 & 17,04 & 14,33 & 13,06 \\
\hline
\end{tabular}

Fonte: Elaboração própria a partir dos dados do ITBI fornecidos pela PBH e IPEAD UFMG. 
Gráfico 3 Variação anual dos preços dos apartmentos (em termos nominais) nos quantis - Belo Horizonte - 1995-2012

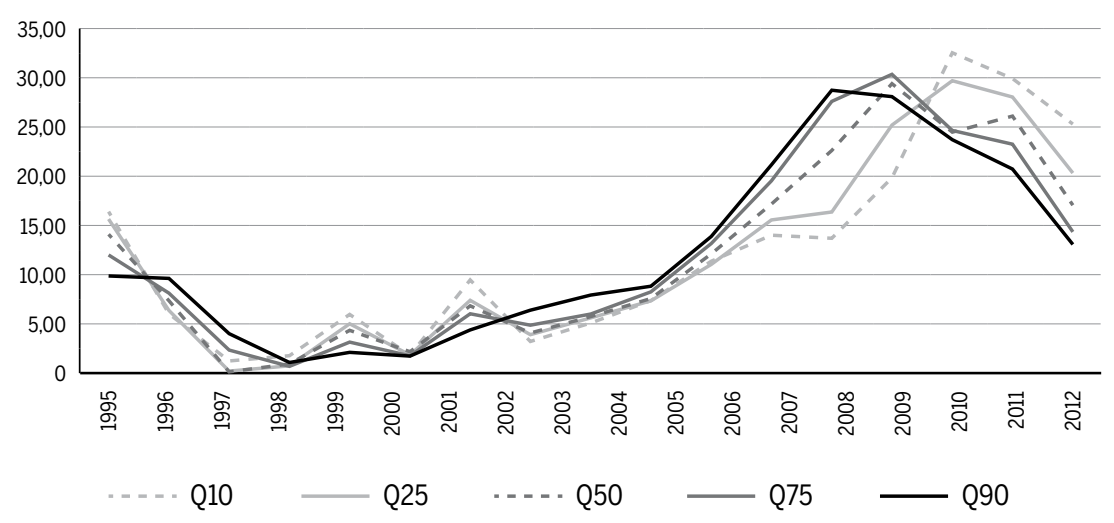

Fonte: Elaboração própria a partir dos dados do ITBI fornecidos pela PBH e IPEAD UFMG.

\subsubsection{A valorização imobiliária em Belo Horizonte frente à conjuntura econômica}

Em termos de valorização imobiliária, o período do trabalho pode ser divido em dois subperíodos. Entre 1995 e 2004, à exceção dos dois primeiros anos, a valorização imobiliária esteve abaixo da inflação (Índice Nacional de Preços ao Consumidor, IPCA) para os diversos quantis. Esse período foi marcado pela pequena disponibilidade de crédito imobiliário, uma vez que o Sistema Financeiro da Habitação (SFH) encontrava-se em reestruturação (Aguiar, 2014). Contribuíram também para o baixo dinamismo do mercado imobiliário no período, a estagnação da renda média das famílias da $\mathrm{RMBH}$, o alto patamar da taxa básica de juros (SELIC) e as constantes crises internacionais que afetaram a economia brasileira, resultando no pouco dinamismo econômico. Nessa conjuntura, a valorização nominal anual média do preço dos apartamentos, em todos os segmentos, foi menor que a inflação média do período (Tabela 4).

A partir de 2005, inicia-se um novo período marcado pela valorização real do preço dos apartamentos. Contribuiu para esse cenário a reestruturação do SFH iniciada em 1997 com a Lei no 9.514, que instituiu os certificados de recebíveis imobiliários e as companhias securitizadoras (Aguiar, 2014; Cardoso; Leal, 2009). Em 2005, quando as controvérsias jurídicas 
em torno do instituto da alienação fiduciária foram sanadas, com a Lei no 10.931 de 2014, a reestruturação do SFH foi concretizada (Aguiar, 2014) e, consequentemente, o valor das operações de crédito imobiliário ao setor privado passou a crescer acima da inflação. ${ }^{16}$

Tabela 4 Valorização dos apartamentos em Belo Horizonte, taxa de crescimento do crédito imobiliário e IPCA para períodos selecionados

\begin{tabular}{|c|c|c|c|c|c|c|c|}
\hline \multirow[t]{2}{*}{ Período } & \multicolumn{5}{|c|}{$\begin{array}{r}\text { Valorização média dos preços } \\
\text { dos apartamentos (\%) }\end{array}$} & \multirow{2}{*}{$\begin{array}{r}\text { Taxa de crescimento } \\
\text { média do crédito } \\
\text { imobiliário (\%) }\end{array}$} & \multirow[t]{2}{*}{ IPCA (\%) } \\
\hline & Q10\% & Q25\% & Q50\% & Q75\% & $Q 90 \%$ & & \\
\hline $1995-2004$ & 5,54 & 5,08 & 4,97 & 4,91 & 5,16 & $-6,12$ & 7,56 \\
\hline 2005-2008 & 11,55 & 12,5 & 14,71 & 16,9 & 17,89 & 22,97 & 4,79 \\
\hline 2009 & 19,83 & 25,18 & 29,4 & 30,35 & 28,08 & 45,71 & 4,31 \\
\hline $2010-2012$ & 29,22 & 25,95 & 22,47 & 20,65 & 19,07 & 45,95 & 6,08 \\
\hline
\end{tabular}

Fonte: Elaboração própria a partir de dados do ITBI fornecidos pela PBH, IPEAD UFMG e IPEAdata.

Entre 2005-2012, além do expressivo aumento nas operações de crédito imobiliário, contribuíram para a valorização imobiliária os ganhos reais nos rendimentos das famílias da RMBH e a queda na taxa básica de juros (Aguiar, 2014). Somado a isso, houve uma reestruturação no mercado de companhias de incorporação imobiliária, com as grandes empresas abrindo capital e adquirindo empresas menores. Essas empresas, com mais recursos, passaram a adquirir terrenos para novos empreendimentos e a investir nos mercados de famílias de rendimento médio e baixo (Aguiar, 2014; Cardoso e Leal, 2009). Nessa conjuntura, os apartamentos em Belo Horizonte valorizaram de forma intensa $(13,72 \%)^{17}$, acima da inflação média do período, que ficou em $5,21 \%$.

Entre 2005 e 2008, os apartamentos dos quantis superiores, $\mathrm{O} 75 \%$ e Q90\%, foram os que obtiveram maior valorização. Ou seja, no primeiro momento o aumento da demanda concentrou-se nos segmentos superiores do mercado imobiliário cujos preços encontravam-se em um patamar baixo, consequência da conjuntura anterior desfavorável. Como resultado o aumento de preços foi mais acentuado nesses segmentos. Porém, os de-

16 Para o acumulado do período (2005-2012) o crédito imobiliário cresceu em média 33,94\%. 17 A valorização média para todos os segmentos foi calculada pela média geométrica simples da média anual dos diversos segmentos. 
mais segmentos do mercado de apartamentos também registraram valorização real, embora mais modestas (Tabela 4).

O ano de 2009 marcou uma transição no padrão de valorização imobiliária de Belo Horizonte. O segmento superior (O90\%) deixou de ser o mais dinâmico, em detrimento dos segmentos intermediários $(\mathrm{Q} 75 \%$ e O.50\%). Essa perda de dinamismo do segmento mais alto parece ser mais uma consequência da grande valorização anterior (que tornaram os valores extremamente altos) do que efeito da crise mundial do subprime, uma vez que os segmentos mais baixos ( $\mathrm{Q} 25 \%$ e $\mathrm{Q} 10 \%$ ) exibiram aumentos na taxa de valorização imobiliária. Em 2009, embora a crise tenha afetado a economia brasileira, esse contágio não atingiu o mercado imobiliário belo-horizontino, uma vez que o crédito imobiliário continuou crescendo em ritmo acelerado (45,71\% em termos nominais) assim como a renda média da $\mathrm{RMBH}\left(7,87 \%\right.$ em termos nominais). ${ }^{18}$

Nos três últimos anos do período (2010-2012), houve uma reversão no padrão quantílico da valorização imobiliária. Em 2009, o Governo Federal adotou um conjunto de políticas econômicas anticíclicas, de cunho keynesiano, visando evitar que os efeitos da crise contagiassem a economia brasileira. Duas dessas políticas afetaram diretamente o mercado imobiliário:

a) O Programa Minha Casa, Minha Vida (PMCMV), cujo objetivo principal era a construção e o financiamento de moradias para famílias de baixa renda (até $\mathrm{R} \$ 4.600,00$ );

b) A expansão do crédito imobiliário dos bancos públicos, cuja participação no mercado de financiamento imobiliário passou a ser predominante, em contraste com o período anterior (2005-2008), no qual a maior participação no financiamento imobiliário foi dos bancos privados (Araújo, 2012).

Essas políticas tiveram como um dos resultados aumentar a demanda por imóveis dos segmentos inferiores, resultando em valorização maior nesses segmentos (Tabela 4). Nesse período, a maior valorização nominal média se deu no segmento mais baixo (Q10\%), 25,95\%, e a menor valorização foi no segmento mais alto (090\%), 19,07\%. De todo modo, a valorização imobiliária nominal em todos os segmentos do mercado, entre 2010 e 2012, superou a inflação média do período, 6,08\% (Tabela 4). 


\subsubsection{Comparação dos índices estimados com a literatura nacional}

Paixão (2015) utilizou o método hedônico TD para estimar a valorização real nos preços dos bens imóveis para Belo Horizonte, entre 1995 e 2013, utilizando regressão de mínimos quadrados ordinários. O autor estimou uma desvalorização real média de $2,25 \%$ no preço dos apartamentos no período, com um pico negativo no ano de 1999 (-13,72\%), quando houve a maxidesvalorização do Real. Comparando os resultados dos exercícios quantílicos aqui propostos, tomando o período de 1995-2003, temos resultados semelhantes aos encontrado por Paixão (2015). A valorização nominal em todos os quantis ficou abaixo da inflação. Assim, como em Paixão (2015), o ano de 1999 foi o que a valorização nominal mais se descolou do IPCA, para todos os quantis.

Rozenbaum (2009) estimou um índice de preços para imóveis para o município do Rio de Janeiro, no período entre 1997-2007, utilizando um conjunto de regressões hedônicas para diferentes localizações da cidade, a partir de regressões de mínimos quadrados pelo método APTD. Para o período analisado, o autor concluiu que possuir um imóvel no Rio de Janeiro constituía-se em uma forma de se proteger dos efeitos da inflação, uma vez que a valorização imobiliária nominal esteve próxima da variação do índice nacional de preços. Todavia, a valorização imobiliária, na capital fluminense, esteve em patamar bastante inferior ao da taxa básica de juros (SELIC). Quando comparamos a valorização imobiliária estimada no Rio de Janeiro com os índices quantílicos aqui mensurados, temos que para Belo Horizonte, entre 1997 e 2007, também se aplica à conclusão de Rozenbaum (2009). Ou seja, nesse período a variação dos preços dos apartamentos em $\mathrm{BH}$ esteve próxima à inflação, nos diversos quantis.

\section{Conclusão}

Este estudo teve como objetivo estimar índice de preços para apartamentos em Belo Horizonte, entre 1995 e 2012, para diversos segmentos do mercado imobiliário. Para isso, utilizou-se a metodologia de preços hedônicos na estimação dos índices de preços, a partir das técnicas de regressão quantílica. A regressão quantílica é a ferramenta econométrica mais adequada para construir índice de preços para mercados segmentados, 
como é o imobiliário. Entre os métodos hedônicos existentes para mensurar índice de preços optou-se pela estimação de regressões com dummy de tempo para períodos adjacentes. A estimação foi feita seguindo o método adjacent-period-time-dummy, no qual se estima uma regressão para cada par de anos. Esse método foi escolhido por gerar resultados mais estáveis que o método da imputação hedônica, no qual o índice é obtido a partir de um conjunto de regressões cross-section.

Os resultados apontam que no período 1995-2004, marcado tanto pela falta de um marco institucional para o financiamento imobiliário quanto por um ambiente macroeconômico incerto, a valorização dos imóveis foi modesta em todos os segmentos, em muitos anos abaixo da inflação. Contribuíram para esse cenário o alto patamar das taxas de juros e os ganhos de renda modestos dos trabalhadores.

Entre 2005 e 2012, a valorização imobiliária passa a ser intensa, acima da inflação em todos os segmentos. Um novo marco institucional para o financiamento imobiliário, em discussão desde 1997, entrou em vigor, em 2004. Como consequência, as operações de crédito imobiliário passaram a crescer rapidamente. Entre 2004-2008, o ambiente macroeconômico ficou mais estável, marcado pelo crescimento do PIB, da renda das famílias e pela queda nas taxas de desemprego e da taxa básica de juros da economia. Nesse período, os imóveis dos quantis superiores obtiveram maior valorização vis-à-vis aos imóveis dos segmentos mais baixos. O fácil acesso ao crédito imobiliário e os aumentos de renda permitiram que a demanda por apartamentos dos segmentos mais altos se elevasse, levando à uma expressiva valorização nesses segmentos. Houve também valorização relevante, porém mais modesta, nos apartamentos dos segmentos mais baixos.

Em 2009, o Governo Federal brasileiro elaborou um pacote de medidas anticíclicas em resposta à crise financeira mundial iniciada em 2008. No bojo desse pacote estavam duas políticas que afetavam o mercado imobiliário: um programa para aquisição subsidiada de imóveis para população de baixa renda (Programa Minha Casa, Minha Vida) e o aumento na oferta de crédito dos bancos públicos (Caixa Econômica Federal e Banco do Brasil). O resultado foi uma inversão no padrão de valorização quantílica dos imóveis. Os segmentos mais baixos passaram a valorizar a taxas maiores que os segmentos superiores. Porém, mesmo com uma valorização mais baixa os imóveis dos segmentos superiores continuaram a se valorizar a taxas significativamente mais altas que a inflação verificada. 


\section{Referências}

ABRAMO, P. Mercado e ordem urbana: do caos à teoria da localização residencial. Rio de Janeiro: Bertrand do Brasil, 2001.

ABRAMO, P. A cidade com-fusa: a mão inoxidável do mercado e a produção da estrutura urbana nas grandes metrópoles latino-americanas. Revista Brasileira de Estudos Urbanos e Regionais, v. 5, p. 12-32, 2008.

AGUIAR, M. M. de. Crédito e mercado imobiliário no Brasil: fatores institucionais e macroeconômicos (1964-2013). In: XVI SEMINÁRIO DE ECONOMIA MINEIRA, Diamantina, 2014. Anais... Diamantina: CEDEPLAR/UFMG, 2014.

ALMEIDA, R. P.; MONTE-MÓR, R. L. M.; AMARAL, P. V. M. Implosão e explosão na Exópolis: evidências a partir do mercado imobiliário da RMBH. Nova Economia, v. 27, n. 2, p. 323-350, 2017.

ALONSO, W. Location and land use. Cambridge MA: Harvard University Press, 1964.

ARAÚJO, V. L. de. Preferência pela liquidez dos bancos públicos no ciclo de expansão do crédito no Brasil: 2003-2010. Brasília: IPEA, 2012. (Texto para Discussão 1717)

BAILEY, M. J.; MUTH, R. F.; NOURSE, H. O. A Regression method for real estate price index construction. Journal of the American Statistical Association, v. 58, n. 34, p. 933-942, 1963.

BARTHÉLÉMY, F.; ROSIERS, F.; BARONI, M. Market heterogeneity and the determinants of Paris apartment prices: a quantile regression approach. In: EUROPEAN REAL ESTATE SOCIETY CONFERENCE, 2013, Viena. Anais... Viena: EURES, 2013.

BIANCONI, M.; YOSHINO, J. A. House price indexes and cyclical behavior. International Journal of Housing Markets and Analysis, v. 6, n. 1, p. 26-44, 2013.

BRUECKNER, J.K.; THISSE, J.-F; ZENOU, Y. Why is central Paris rich and downtown Detroit poor? An amenity-based theory. European Economic Review, v. 43, p. 91-107, 1999.

BUCHINSKY, M. Recent advances in quantile regression models: a practical guideline for empirical research. The Journal of Human Resources, v. 33, n. 1, p. 88-126, 1998.

CAMERON, A. C.; TRIVEDI, P. K. Microeconometrics: method and applications. Cambridge: Cambridge Press, 2005.

CAMERON, A. C.; TRIVEDI, P. K. Microeconometrics using stata. Stata Press, Revised Edition, 2010.

CARDOSO, A. L.; LEAL, J. A. Housing markets in Brazil: recent trends and governmental responses to the 2008 crisis. In: ISA INTERNATIONAL HOUSING CONFERENCE, Glasgow, 2009. Anais... Glasgow: ISA, 2009.

COULSON, N. E.; McMILLEN, D. P. The dynamics of intraurban quantile house prices indexes. Urban Studies, v. 44, n. 8, p. 1571-1537, 2007.

COURT, A. Hedonic price indexes with automotive examples. The dynamics of automobile demand. General Motors, New York, p. 98-119, 1939.

CYRILLO, G. B. Mercado imobiliário informal e seus mecanismos de operação: a vila Acaba Mundo, Belo Horizonte. Dissertação (Mestrado em Arquitetura e Urbanismo) - Programa de Pós-Graduação em Arquitetura e Urbanismo, Universidade Federal de Minas Gerais, 2011.

DENG, Y.; McMILLEN, D. P.; SING, T. F. Private residential price indices in Singapore: 
a matching approach. Regional Science and Urban Economics, v. 42, n. 3, p. 485-494, 2012.

DIEWERT, W. E. The Paris OECD-IMF workshop on real estate price indexes: Conclusions and Future Directions. In: DIEWERT, E. Erwin et al. (Ed.). Price and Productivity Measurement: volume 1 - housing. Trafford Press, 2009. Disponível em: <http://faculty.arts.ubc. ca/ediewert/dp0701.pdf>. Acesso em: fev. 2010.

ELS, M.; FINTEL, D. V. Residential property price in a submarket of South Africa: separating real returns from attribute growth. South African Journal of Economics, v. 78, n. 4, p. 418-436, 2010.

FREEMAN, M. Hedonic prices property values and measuring environmental benefits: a survey of the issues. The Scandinavian Journal of Economics, v. 81, n. 2, p. 154-173, 1979.

FUJITA, M.; OGAWA, H. Multiple equilibria and structural transition of non-monocentric urban configurations. Regional Science and Urban Economics, v. 12, n. 2, p. 161-196, 1982.

FURTADO, B. Mercado imobiliário e a importância das características locais: uma análise quantílico-espacial de preços hedônicos em Belo Horizonte. Análise Econômica, ano 25, n. 47, p. 71-98, 2007.

GATZLAFF, D. H.; LING, D. C. Measuring changes in local house prices: an empirical investigation of alternative methodologies. Journal of Urban Economics, v. 35, p. 221-244, 1994.

GONZÁLEZ, M. A. S. Variação qualitativa e índice de preços na análise do comportamento recente dos aluguéis em Porto Alegre (1994-1997). Análise Econômica, v. 15, n. $28,1997$.

GONZÁLEZ, M. A. S. Fontes alternativas para estudos intra-urbanos: ITBI. In: VII ENCONTRO NACIONAL DA ANPUR, 1997. Recife: Anais... Recife: Associação Nacional de Pós-Graduação em Planejamento Urbano e Regional, 1997a.

GOODMAN, A.; THIBODEAU, T. Age-related heteroskedasticity in hedonic price equations. Journal of Housing Research, v. 6, n. 1, p. 25-42, 1995.

GRILICHES, Z. Hedonic Price Indexes for Automobiles: an econometric of quality change. The Price Statistics of the Federal Government, General Series No. 73. Columbia Univ. Press for the National Bureau of Economic Research, New York, p. 137-196, 1961.

GRILICHES, Z. Introduction: hedonic price indexes revisited. In: (Ed.). Prices indexes and quality change: studies in new methods of measurment. Cambridge: Harvard University Press, 1971.

HILL, R. Hedonic price indexes for residential housing: a survey, evaluation and taxonomy. Journal of Economic Surveys, v. 27, n. 1, p. 879-914, 2013.

HILL, R.; MELSER, D. Hedonic imputation and the price index problem: an application to housing. Economic Inquiry, v. 46, n. 4, p. 593-609, 2008.

HILL, R.; MELSER, D.; SYED, I. Measuring a boom and bust: the Sydney housing market 2001-2006. Journal of Housing Economics, v. 18, n. 3, p. 193-225, 2009.

HOESLI, M.; GIACCOTTO, C.; FAVARGER, P. Three new real estate price indexes for Geneva, Switzerland. Journal of Real Estate Finance and Economics, v. 15, n. 1, p. 93-109, 1997.

KOENKER, R.; HALLOCK, K. Quantile regression. Journal of Economic Perspectives, v. 15, n. 4, p. $143-156,2001$.

MAURER, R.; PITZER, M.; SEBASTIAN, S. Hedonic price indices for the Paris housing market. Allgemeines Statistisches Archiv, v. 88, p. 303-326, 2004.

McMILLEN, D. P. Local quantile house price indices. AREUEA MEETINGS, 2014, Tel Aviv 
University, July, 3, 2014. Anais... Tel Aviv: AREUEA, 2014.

MEGBOLUGBE, I.; HOEK-SMIT, M.; LINNEMAN, P. Understanding neighborhood dynamics: a review of the contributions of Willian G. Grigsby. Urban Studies, v. 3, n. 10, p. 17791795, 1996.

MUTH, R.F. Cities and housing. Chicago: University of Chicago Press, 1969.

PAIXÃO, L. A. Índice de preços hedônicos para imóveis: uma análise para o município de Belo Horizonte. Revista de Economia Aplicada, v. 19, n. 1, p. 5-29, 2015.

PAVESE, P. Hedonic housing price indices: the turinese experience. Revista di Politica Economica, v. 95, n. 6, p. 113-148, 2007.

RÊGO, P. A. Dinâmica dos aluguéis residenciais urbano entre 1995 e 2007 no Brasil: construção de índice e identificação dos fatores de influências. Dissertação (Mestrado em Ciências Econômicas) - Faculdade de Economia, Administração, Contabilidade e Ciência da Informação e Documentação, Universidade de Brasília, 2009.

ROSEN, S. Hedonic price and implicit markets: product differentiation in pure competition. Journal of Political Economy, v. 82, n. 1, p. 35-55, 1974.

ROZENBAUM, S. IMPA - Índice municipal de preços de apartamentos: proposta e metodologia. Tese (Doutorado em Administração de Empresas) - Programa de Pós-Graduação em Administração de Empresas, Pontifícia Universidade Católica do Rio de Janeiro, 2009.

ROZENBAUM, S.; MACEDO-SOARES, T. D. L. V. A. Proposta para a construção de um índice de preços de imóveis a partir dos lançamentos imobiliários de condomínios residenciais. Revista de Administração Pública, v. 41, n. 6, 2007.

VON THUNEN, J. Isolated state. New York, Pergamon Press, 1966[1826].

TRIPLETT, J. Handbook on hedonic and quality adjustments in price indexes: special application to information technology products. Paris: Organisation for Economic Co-operation and Development (OECDE), 2004. (Working Paper 2004/9).

WAUGH, F. V. Quality factors influencing vegetable prices. Journal of Farm Economics, v. 10, n. 2, p. 185-196, 1928.

ZIETZ, J.; ZIETZ, E. N.; SIRMANS, G. S. Determinants of house prices: a quantile regression approach. Journal of Real Estate Finance and Economics, v. 37, n. 4, p. 317-333, 2008.

\section{Sobre os autores}

Luiz Andrés RibeiroPaixão - luiz.paixao@ibge.gov.br

Instituto Brasileiro de Geografia e Estatística (IBGE) - Rio de Janeiro, RJ, Brasil.

ORCID: https://orcid.org/0000-0002-6378-9518.

Viviane Luporini-viviane.luporini@ie.ufrj.br

Universidade Federal do Rio de Janeiro (UFRJ) - Rio de Janeiro, RJ, Brasil.

ORCID: https://orcid.org/0000-0001-9629-5058.

O IBGE é isento de qualquer responsabilidade pelas opiniões, informações, dados e conceitos emitidos neste artigo, que são de exclusiva responsabilidade do autor.

\section{Sobre 0 artigo}

Recebido em 05 de setembro de 2016. Aprovado em 03 de abril de 2018. 


\section{APÊNDICE}

Tabela A1 Transações com apartamentos por bairros* de Belo Horizonte - 1995-2012

\begin{tabular}{lrr}
\hline Bairro & Número de transações & Participação(\%) \\
\hline Buritis & 14758 & 4,57 \\
\hline Lourdes & 11107 & 3,44 \\
\hline Castelo & 10965 & 3,39 \\
\hline Sagrada Família & 9932 & 3,07 \\
\hline Santo Antônio & 9305 & 2,88 \\
\hline Sion & 8436 & 2,61 \\
\hline Serra & 8013 & 2,48 \\
\hline Savassi & 7380 & 2,28 \\
\hline Centro & 7281 & 2,25 \\
\hline Padre Eustáquio & 7226 & 2,24 \\
\hline Estoril & 6936 & 2,15 \\
\hline Gutierrez & 6197 & 1,92 \\
\hline Santa Efigênia & 5697 & 1,76 \\
\hline Santo Agostinho & 5523 & 1,71 \\
\hline Cidade Nova & 5420 & 1,68 \\
\hline Anchieta & 5202 & 1,61 \\
\hline Nova Suíssa & 4835 & 1,50 \\
\hline Palmares & 4619 & 1,43 \\
\hline Floresta & 4601 & 1,42 \\
\hline Jardim América & 4534 & 1,40 \\
\hline Ouro Preto & 4497 & 1,39 \\
\hline Funcionários & 4234 & 1,31 \\
\hline Camargos & 4046 & 1,25 \\
\hline Belvedere & 3645 & 1,13 \\
\hline Caiçara-Adelaide & 3609 & 1,05 \\
\hline Santa Mônica & 3405 & 1,03 \\
\hline Santa Amélia & 3327 & \\
\hline For & & \\
\hline
\end{tabular}

Fonte: Elaboração própria a partir de dados do ITBI fornecidos pela PBH e IPEAD UFMG.

* Foram tabulados apenas os bairros com participação maior ou igual a 1,0\%. 
Figura A1 Mapa da participação (\%) de cada bairro no total de transações com apartamentos para Belo Horizonte - 1995-2012

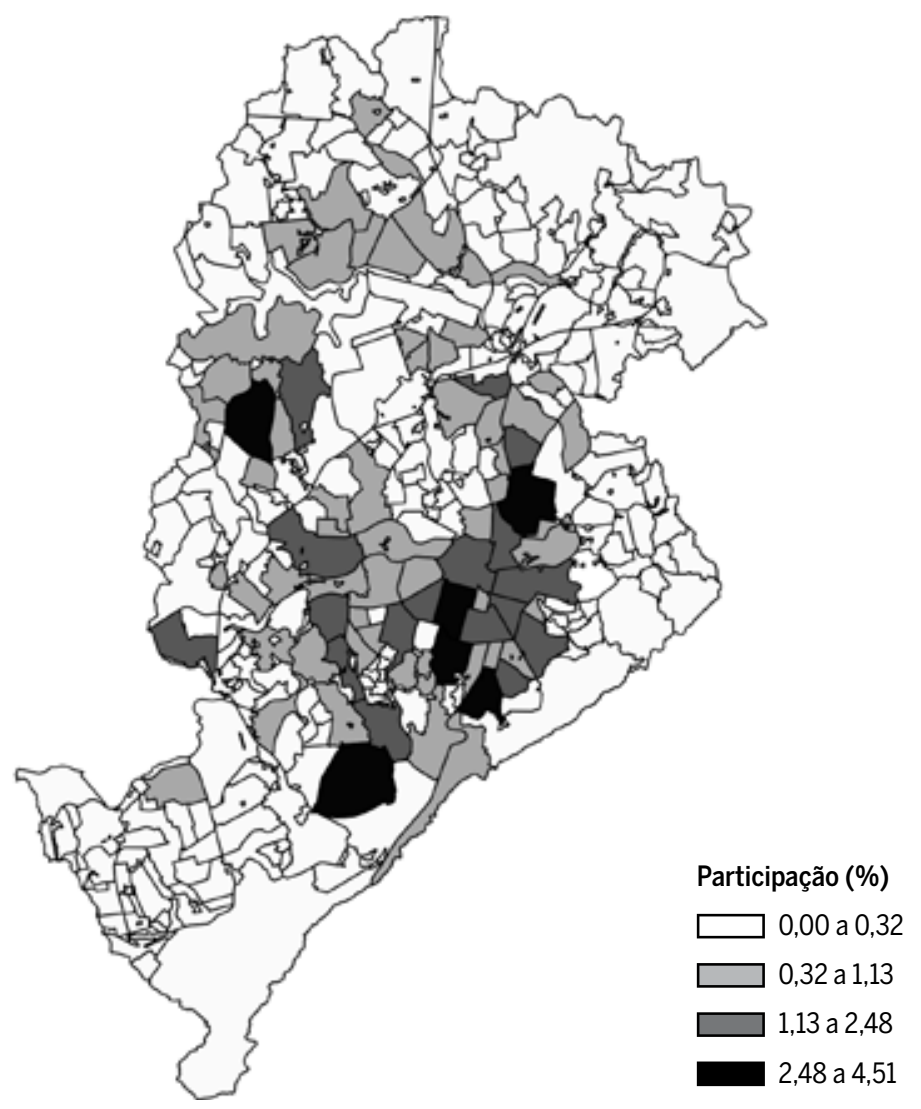

